\title{
Instruments of health and harm: how the procurement of healthcare goods contributes to global health inequality
}

\author{
Mei L Trueba $\odot,{ }^{1}$ Mahmood F Bhutta, ${ }^{2}$ Arianne Shahvisi $\oplus^{3}$
}

${ }^{1}$ Global Health and Infection, Brighton and Sussex Medical School, Falmer, Brighton, UK ${ }^{2}$ Department of Ear, Nose and Throat (ENT), Brighton and Sussex University Hospitals NHS Trust, Brighton, UK ${ }^{3}$ Ethics, Brighton and Sussex Medical School, Falmer, Brighton, UK

\section{Correspondence to} Dr Mei L Trueba, Global Health and Infection, Brighton and Sussex Medical School, Falmer Brighton BN1 9PX, UK; m.trueba@bsms.ac.uk

Received 7 April 2020 Revised 1 July 2020 Accepted 3 July 2020 Published Online First 24 August 2020
Check for updates

(C) Author(s) (or their employer(s)) 2021. No commercial re-use. See rights and permissions. Published by BMJ.

To cite: Trueba ML, Bhutta MF, Shahvisi A. $J$ Med Ethics

2021;47:423-429.

\section{ABSTRACT}

Many healthcare goods, such as surgical instruments, textiles and gloves, are manufactured in unregulated factories and sweatshops where, amongst other labour rights violations, workers are subject to considerable occupational health risks. In this paper we undertake an ethical analysis of the supply of sweatshop-produced surgical goods to healthcare providers, with a specific focus on the National Health Service of the United Kingdom. We contend that while labour abuses and occupational health deficiencies are morally unacceptable in the production of any commodity, an additional wrong is incurred when the health of certain populations is secured in ways that endanger the health and well-being of people working and living elsewhere. While some measures have been taken to better regulate the supply chain to healthcare providers in the UK, further action is needed to ensure that surgical goods are sourced from suppliers who protect the labour and occupational health rights of their workers.

\section{INTRODUCTION}

For those of us living in the United Kingdom (UK) one of the most obvious effects of economic globalisation is that the products we have come to rely on are generally sourced and processed where labour and raw materials are inexpensive and readily available. However, cheap production costs frequently track poor labour regulation and/or weak enforcement of existing regulation, ${ }^{1-3}$ which raises concerns about justice for workers. These concerns have led to high-profile campaigns in favour of ethical trade across various industries (such as mining, garments or agricultural products), but despite the fact that poor working conditions have also been observed in global procurement networks within the healthcare industry, this sector has received little attention or critique.

Over a decade ago, it was revealed that the provision of goods to healthcare systems in high-income countries often involves products manufactured under precarious labour conditions, including surgical instruments and medical gloves. ${ }^{45}$ While some procurers and buyers have made efforts towards addressing this, they represent a very small proportion of global healthcare purchasing. ${ }^{6}$ Work is still needed to guarantee that healthcare goods across the world are ethically sourced, and that they do not damage the health, well-being and socioeconomic prospects of those who manufacture them.

The manufacture of healthcare products in precarious working conditions is concerning because all instances of precarious work are concerning, but also because benefitting from the harms experienced by others is morally problematic. In the case of healthcare-related goods there is a further specific injustice, and it is this which our paper focusses on. We argue that it is particularly troubling to make use of healthcare goods which can facilitate or enhance the health and well-being of some, but which were produced under conditions which jeopardise the health and well-being of those who made them (and that of their dependants). We show that the use of healthcare products produced under poor working conditions amounts to an extraction of good health and economic prospects from particular social groups in order to accentuate the health and economic outcomes of other groups, or the production of good health in one region at the expense of negative health outcomes in other regions. This trend exemplifies the way in which health systems and governments not only accept, but also benefit from health inequality, which constitutes an extraction of value not unlike the appropriation of resources which underwrites global inequality more generally. We conclude that it is immoral for nation-states and healthcare systems to seek to deliver good health to some at the cost of poor health and economic prospects to others, and recommend that governments take additional measures to ensure that their products were not produced in ways which endanger the health and well-being of workers and their dependents.

In the interest of retaining a sharp focus within this paper, we will not discuss manufacture and distribution of personal protective equipment (PPE), where supply chains have come under unprecedented pressure during the current COVID-19 pandemic. Whereas many of our arguments can be applied to the supply of PPE (and other scholars may take up the task of discussing these more specifically), our study highlights the issues that apply to surgical supply chains more broadly (including, but not limited to, PPE). We also do not describe here the moral issues relating to precarious employment and unregulated sweatshop or factory work more generally. Others have done so elsewhere (see for example ${ }^{7-9}$ ). Rather, we start from the premise that such work is morally unacceptable, and focus on the particular wrong that is committed in the procurement of healthcare products produced under these conditions. Further, while ethical shortcomings have been identified in the production of a range of healthcare goods, here, we focus specifically on surgical goods. Our paper discusses these issues in the context of the UK's National Health Service 
(NHS). Not only are the authors based in the UK, but as a health system funded by general taxation and national insurance contributions, the ethics of procurement within the NHS is a matter of public interest.

Our article is structured as follows. In the next section we offer some background on global surgical procurement and supply chains, describe the evidence for unethical labour in the manufacture of surgical goods and critically outline some of the efforts made in the UK to address these concerns. In the following section, we describe and critique the unjust global distribution of health, noting that the production of good health in high-income settings too often depends on poor health outcomes in low-income settings. The third section presents the case for more robust ethical procurement within the NHS. The final section concludes by making recommendations for healthcare goods procurers, specifically, that these goods are fairly traded and only sourced from producers and suppliers who put in place systems to protect the occupational health and wider labour rights and entitlements of their workers.

\section{UNETHICAL LABOUR PRACTICES IN THE PROCUREMENT OF SURGICAL GOODS}

The global market for surgical instruments was estimated to be worth US\$ 5.9 billion in $2013,{ }^{10}$ rose to US\$ 10.70 billion in $2017^{11}$ and it is expected to reach US\$ 38.3 billion by $2025 .^{12}$ In 2016, surgical sutures, staples and staplers constituted the largest share of this market, followed by obstetrics, gynaecology and cardiovascular instruments, owing to the large number of caesarean surgeries being performed worldwide and the rising prevalence of chronic diseases. Canada and the USA dominated the global market, followed by Europe (in particular Germany and the UK), Japan, China, India, Brazil and Mexico. ${ }^{12} 13$ The leading suppliers of these surgical goods to Europe are registered in the USA, the Netherlands and Belgium, followed by several low- and middle-income countries (LMICs) that directly export substantial volumes of surgical instruments to this regionmainly Mexico, China, Malaysia, Costa Rica, Thailand, Pakistan, India and Vietnam. In 2015, the majority of procurement to Europe proceeded through long chains of buyers and intermediaries, while $12 \%$ of imports came directly from LMICs. ${ }^{14}$

In the UK, the exact expenditure on surgical goods within the NHS is not publicly available, but the procurement of surgical goods and services stood at $£ 30$ billion annually in $2015,{ }^{15}$ with the total healthcare expenditure (from both public and private sectors) standing at $£ 197.4$ billion in $2017 .{ }^{16}$ As with many other healthcare providers worldwide, procurement in the UK occurs through direct supply or via local, regional or national procurement hubs which in turn rely on suppliers or intermediaries at national, regional and international levels. In England, the largest procurement hub for surgical goods is the NHS Supply Chain, which has awarded contracts to UK and overseas suppliers importing goods from factories and sweatshops around the world. Regardless of their country of formal registration, many suppliers to the NHS outsource the manufacture of their products to international suppliers, mainly from: the USA and Europe (disposable products and textiles); Mexico (dressings and plasticbased products such as gloves and masks); and Asia (textiles, dressings, gloves, surgical instruments, syringes, needles, and so on). ${ }^{15}$ In the case of the gloves used every day in NHS clinics and operating theatres, most production is outsourced to factories in Malaysia and Thailand, ${ }^{17}$ while a significant proportion of metal surgical instruments used in the UK are produced in the city of Sialkot, in north-eastern Pakistan. ${ }^{18}$
With the slogans 'delivering value to the NHS', 'better procurement, better value, better care' and 'doing it right: savings without compromising on care', ${ }^{19}$ the procurement strategy of the NHS Supply Chain has traditionally focussed on making savings through price comparisons and benchmarking. For instance, as an example of 'efficient procurement' and of 'doing things right', the 2013 procurement strategy advises that the NHS could generate savings of up to 38 per cent on the approximately $£ 25$ million spent on sterile surgeon's gloves by undertaking product/producer substitution. The document goes on to suggest that these savings could be used to reduce the reliance of the NHS on costly agency staff, or could be a major driver for growth in the economy.

In other words, the procurement strategy is dominated by considerations of cost-cutting, and 'doing things right' is meant in the narrow sense of ensuring that quality goods are obtained at the lowest possible price, an objective which is deemed to be in the public interest. While cutting the expenses associated with healthcare goods may be considered a prudent strategy for the NHS, which is after all answerable to the taxpayers who fund it, there are morally relevant externalities that are absent from this narrative. Aggressive price comparison and global supply competition are known to have a significant effect on workers' labour conditions and health and safety, producing and perpetuating jobs that are very often precarious, insecure and unhealthy. ${ }^{20}$ As this global competition pushes governments, manufacturers and suppliers to lower prices, basic labour rights are overlooked in order to attract buyers and procurement contracts. ${ }^{120}$ As the next subsection illustrates, the thousands of healthcare goods used every day to promote health and economic prospects in the UK too often damage the health and socio-economic prospects of people living and working elsewhere.

\section{Labour and occupational health violations in the manufacture of surgical goods}

Produced in cooperatives, unregulated factories or sweatshops in Pakistan, Mexico, Thailand or the USA, the jobs generated under this open global competition are often unregulated, insecure and highly unhealthy, ${ }^{136}$ and often imperil, rather than safeguard, the health and well-being of workers and their dependants both in the short-term and long-term. This tends to be the case whether or not states have ratified the International Labour Organization's conventions ${ }^{18}$ and regardless of the existence of adequate legislation and enforcement mechanisms. ${ }^{121}$ Since 2007, NGOs such as the British Medical Association, Swedwatch and Finnwatch have produced reports on labour rights violations and precarious employment in the healthcare manufacturing sector which supplies the NHS. The most notable examples are the Pakistani surgical instruments and Malaysian gloves manufacturing industries. In Pakistan, the manufacture of surgical instruments is associated with non-compliance with local labour laws with regard to minimum wage and excessive overtime, unfair contractual obligations, widespread child labour and an absence of health and safety protections. ${ }^{4518}$ In Malaysia, the gloves industry is associated with ad hoc employment, poor remuneration, compulsory overtime, insufficient health and safety provisions, anti-union activities and bonded labour of migrant workers involving illegal retention of passports. ${ }^{17}$

There is little information regarding the specific disease burden associated with working on these production lines and, as happens with other industries, attempts at measuring this burden are often obstructed by suppliers, buyers, producers and/ or governments themselves. ${ }^{20} 21$ The limited available evidence indicates that in the manufacture of surgical instruments in 
Pakistan, musculoskeletal problems and injuries are common, sometimes leading to significant impairment, including loss of limbs. ${ }^{5}$ There are serious dangers at various stages of the manufacturing process, including exposure to heavy machinery, hazardous electrical wiring, toxic and corrosive chemicals, metal dust and deafening noise-levels in grinding rooms. ${ }^{518}$ When unmanaged, these occupational hazards can cause cuts and burns to hands and feet, repetitive strain syndrome, trauma to the eye, noise-induced hearing loss, visual loss, electric shocks, chronic obstructive pulmonary disease or lung cancer. ${ }^{22}$ However, as employers are able to freely curb collective-bargaining rights with anti-union policies, ${ }^{18}$ disempowered workers in need of an income often operate machinery that is not regularly checked without any personal or collective protective equipment. ${ }^{18}$ Further, workers' wages are insufficient even by Pakistan's own household income standards ${ }^{5}$ and therefore do not permit regular contributions to social insurance mechanisms that could enable workers access to healthcare or disability benefits.

The manufacture of other healthcare goods presents similar risks. For instance, the manufacture of healthcare textiles has been associated with silicosis and lung cancer, while unprotected glove-manufacturing is associated with exposure to chemical products, temperatures above $45^{\circ} \mathrm{C}$ (and sometimes as high as $70^{\circ} \mathrm{C}$ ), noise levels that can cause hearing loss, skin and eye burns, fume inhalation and other physical impairments associated with repetitive motion and frequent lifting. ${ }^{17}$

In spite of these harms, as happens with other industries, many governments bend existing legislation in their efforts to increase much-needed local and national employment and economic opportunities, manufacturing companies accept these deals to maintain or expand their operations, and poor and disempowered jobseekers often pursue these jobs in the absence of alternatives. ${ }^{20}{ }^{21}$ In order to remain competitive and maintain profits, many suppliers continue to cut costs by outsourcing production to locations where lower wages will be accepted and labour and occupational health regulations can be disregarded. ${ }^{23}$ To maintain contracts with buyers, some industries (eg, Mexican surgical masks manufacturers) have further reduced production costs through eliminating factory operations and instead relying on hundreds of homeworkers who receive no employee benefits and only an insecure income. ${ }^{15}$

\section{Existing efforts towards ethical procurement in the NHS}

Since 2009, ethical sourcing within the NHS Supply Chain has been guided by the Supplier Code of Conduct (SCC), which outlines basic standards in relation to labour rights and worker well-being. According to the NHS Supply Chain, this code is a contractual requirement and any violation of the obligations it stipulates are considered a breach of contract by the supplier. ${ }^{24}$ In response to evidence of continued labour right violations since the implementation of the SCC, the NHS Supply Chain worked closely with various industry bodies and ethical trade organisations to develop the Labour Standards Assurance System (LSAS) in 2011. The LSAS is intended to support the SCC for products where there are documented labour rights violations, such as surgical instruments, gloves and textiles. ${ }^{17}{ }^{18}$ Piloted in 2012 in relation to surgical instruments, LSAS requires suppliers in the NHS supply chain to demonstrate they have systems in place to guarantee the labour and human rights of workers, and helps them to develop rectification plans when necessary. Strengthened by the Modern Slavery Act 2015, which makes companies accountable for labour abuses occurring along their whole chain of operations, the SCC and LSAS quickly became the cornerstone of the NHS Ethical Procurement Strategy.
These recent regulatory changes have led to small demonstrable improvements in some workers' lives. For example, some surgical instrument suppliers subject to the LSAS requirements in Pakistan have demonstrated efforts towards improving labour standards, including minimum wages and paid overtime. ${ }^{18}$ Glove manufacturing audits have also indicated some improvement to working conditions, including formalised contracts, some leave entitlement and minimum wage as per national regulations. ${ }^{17}$ However, these advances are neither widespread nor lasting, and several counts of non-compliance were observed during visits to factories in both Pakistan and Malaysia, primarily regarding working time, production targets and safety measures. ${ }^{17} 18$ Recent media reports have also revealed continued abuse of migrant workers in the Malaysian gloves manufacturing sector, including in factories that are subject to the LSAS standards required by the NHS Supply Chain. ${ }^{17}$ When asked about the challenges they face, Pakistani factory owners and managers highlighted the negative impacts that low payments and volatile contracts have on their ability to comply with labour regulations and invest in safety measures: '...buyers need to understand the costs. They do not want to pay much but have lots of demands. Without sustainable contracts and prices how is it possible for us to improve?'. ${ }^{18}$ Clearly, a key challenge to ethical procurement for the NHS is the NHS Supply Chain's single-minded emphasis on maximising savings.

\section{UNETHICAL PROCUREMENT AND GLOBAL HEALTH INEQUALITIES}

The moral concerns associated with the global system of healthcare goods procurement are various and extend beyond the mere physical health of workers. As Bhutta writes in relation to labour rights violations in the production of surgical goods:

Poor labour conditions should concern all those in healthcare. Work is inextricably correlated to physical and mental well-being: unsafe working conditions risk bodily injury; inadequate remuneration links to malnutrition, poor housing and lack of opportunity. Long or irregular working hours and a lack of respect at work contribute to stress, anxiety and depression. ${ }^{6}$

Globally, most people spend at the very least one-third of their adult lives working. The risks and rewards of that work are strongly determinative not only of the quality of life, health possibilities and economic prospects of individual workers, but also that of their dependants and communities. The risks and rewards of work therefore determine the socio-economic prospects of individuals and nations alike. However, some forms of work are more health-endangering than others. As described in the previous section, the current production of surgical instruments and gloves is particularly health-endangering for workers and traps them and their dependents in cycles of poverty and ill-health. That is ethically concerning in its own right, as part of a broader concern about failures to protect the occupational health and labour rights of low-paid, disempowered workers. But the extent and nature of the ethical concerns it raises change in important ways when one also considers that the intention and the outcome of the production of healthcare goods is to improve the health of those within recipient populations. Under the current system, the workers who produce surgical goods have their health outcomes suppressed via a range of risks to their occupational health and other labour violations, while those for whom the healthcare goods are procured have their health outcomes enhanced. 
Healthcare goods such as gloves and surgical instruments facilitate and enhance the health of many. Having a large stock of sterile gloves and of (often disposable) surgical instruments helps to optimise the safety of clinical examinations and procedures, and minimise the risk of infection. As such, these goods make safe, optimal healthcare possible for those whose healthcare services procure sufficient amounts of these resources. Further, some goods (eg, clinical gloves) are an occupational health measure, as they also protect healthcare workers from discomfort, infection or exposure to toxic substances, therefore healthcare workers also experience a positive health effect as a result of the use of healthcare goods. This is particularly important since the point can be made even more precisely, in that the occupational health of those who produce surgical instruments is endangered even as they produce items that are essential to the occupational health of other workers. This contradictory feature of healthcare goods has become particularly evident during the COVID-19 public health crisis. As the global demand for gloves and masks has risen exponentially, manufacturing factories have upscaled production in precarious conditions despite nationwide lockdowns. ${ }^{25}$

Much like healthcare goods, the occupational health and safety of workers becomes, in this manner, a commodity itself. ${ }^{21}$ This is most vivid when noting that elsewhere in the world, there are shortages of the very same healthcare goods that are so widely available in other settings. For example, shortages of medical gloves have been reported in Nigeria, Indonesia, Zambia, Tanzania and Bangladesh, ${ }^{26-30}$ and shortages of surgical instruments in Brazil, Nigeria, Kenya, Ethiopia and Honduras. ${ }^{31-33}$ As a result of these shortages, some procedures are delayed or precluded, or take place with increased infection risks to service users and clinicians. Even more concerning is the fact that there are severe shortages of healthcare goods in settings known to be significant global producers and exporters. For instance, while Argentina manufactures surgical goods for export to Brazil, many regions in the country (mostly rural and peri-urban) suffer from shortages. ${ }^{13}$ Similarly, while Mexico is the eighth largest global exporter of healthcare goods, the goods produced are not accessible within the Mexican public health system, so that only the $6 \%$ of the population with access to private-sector healthcare can benefit from these products. ${ }^{34} \mathrm{~A}$ similar situation has been noted in Pakistan. Effectively, the workers manufacturing these products (and their dependents) are among those least likely to benefit from them. Worse, manufacturing countries often end up purchasing the final products from importing countries. ${ }^{13}$

In the next subsection, we explore the broader context of global health inequality, and show that the conditions under which healthcare goods are manufactured point to several specific injustices which warrant urgent redress.

\section{Global health inequality}

A public good is a physical or non-physical resource or service that meets human needs or desires and is non-excludable and non-rivalrous. ${ }^{35} \mathrm{~A}$ good being non-excludable means that it is not possible to prevent those who do not pay from benefitting from the good; a good being non-rivalrous means that one person or group's use of the good does not reduce the utility of the good to others. Herd immunity to an infectious disease is a public good, and is easily established to be both non-rivalrous and nonexcludable, likewise for clean air, street lighting, pavements and certain forms of knowledge. Well-funded, free, universal healthcare-that is, the NHS in principle, if not in practice-may be argued to be a public good. It is non-excludable, since everyone who is ordinarily resident in the UK qualifies for it regardless of their level of contribution, and it is non-rivalrous, since (provided it is well-funded), no one person's use of the service precludes anyone else's.

Even if one can argue that healthcare is a public good in the UK (and we will not attempt to take up this challenge here), one certainly cannot argue that health itself is a public good. Healthcare is only one determinant of a person's health, and is often not the most important. Together with rights and entitlements, diet, exercise, living conditions, occupation, socioeconomic status, ethnicity and gender (among other factors) are strongly determinative of a person's health possibilities. ${ }^{236}$ Since these contributors are manifestly not public goods, health itself cannot be a public good, rather, it is a good that is rivalrous and excludable to the extent that these determinants are affected by factors that are rivalrous and excludable, notably, economic considerations which are definitionally so. Understanding health inequalities therefore requires attention to its political economy, especially since healthcare and other health determinants are increasingly marketised and privatised within an ever more globalised economy. ${ }^{37}$ Political economy approaches to health are perhaps best expressed by Nancy Krieger, who writes that "analysis of causes of disease distribution requires attention to the political and economic structures, processes and power relationships that produce societal patterns of health, disease and wellbeing via shaping the conditions in which people live and work" ${ }^{38}$ (p. 168).

At the global scale, health outcomes in different world regions vary dramatically. One can see this for instance in the 34 year gap between the life expectancy of Japan, at the top of the lifeexpectancy table, and Sierra Leone, at the bottom. ${ }^{39}$ The wealth of Global North states enables the health of their citizens; the poverty of Global South states tends to limit the health of their citizens, and a similar dipole is observed within nation-states where socio-economic inequalities determine in-country health inequities. Importantly, the wealth of certain world regions and populations is related to the poverty of others, notably through histories of colonialism, and the present-day neo-colonial global economic system, which tends to concentrate capital in Global North states, elites and corporations. ${ }^{40}$ As Benatar $e t a l^{41}$ note, "the present dominance of perverse market forces on global health" has led to a situation in which "disparities in wealth and health have persisted and, in many places, widened" (p. 646). Globally, health is excludable, rivalrous and uneven because wealth and power are excludable and rivalrous, and are vastly unequal at the global scale.

In this article we are concerned with one particular case within a variety of ways in which health is rivalrous: a reduction in the health of one group is related to an improvement in the health of another group. Such cases seem particularly pernicious, since it is morally troubling that the health of one group should ever be facilitated at the expense of another's.

There are some important analogues to consider. First, the international 'brain drain' of health workers, in which those who are trained in lower-income countries, often at the expense of taxpayers, migrate in search of higher pay, health entitlements and better living and working conditions, and therefore end up benefitting the health of those in destination states, while leaving their own communities with stark shortages of health-workers. ${ }^{42}$ This seems even more problematic when one considers the inconsistency of the migration of medical workers into the NHS and the increasingly draconian restrictions on migrants' access to free NHS care. Clearly, achieving good health for some groups is deemed to justify the poaching of health-workers from communities with a dire need for them, but the people 
of those communities may not access high-quality healthcare if they migrate. ${ }^{43}$ Consider also environmental racism and classism, where polluting activities take place close to, or within, the neighbourhoods of those with low socio-economic status, thereby decreasing their health possibilities in order to protect the health possibilities of those of higher social status. ${ }^{44}$ Finally, consider the global waste trade, in which high-income states pay lower-income states to dispose of, or recycle, their waste, including healthcare waste ${ }^{45}$ and items that are toxic. ${ }^{46}$ It has been reasoned that the cost to the health of those in the Global North renders in situ disposal not worthwhile, given the priorities of Global North people, while the sums that are paid to lowincome states renders the cost to health acceptable. ${ }^{47}$

To see more clearly why these cases are particularly morally concerning, consider the following thought experiment: a new machine is invented that filters dangerous pollutants from the air of a particular wealthy neighbourhood, improving the air quality and therefore the health of those who live in this area. However, the machine requires a team of workers to continually clean the filters, releasing high concentrations of pollutants which they cannot avoid inhaling, causing serious health problems. It seems morally intuitive that we should reject such a 'healthimproving measure' given that it is in fact health-endangering for some. Indeed, calling such a machine a 'health-improving measure' would be a misrepresentation of its total effects, and would amount to an admission that the health of some people was more important than the health of others, which points to an obvious injustice (A utilitarian might argue that the machine would be justifiable if the beneficiaries of the clean air sufficiently outnumbered the workers harmed by it, or if the harms to the workers were relatively minor, but these arguments would be more forceful if the workers were equipped with high standard protective gear to mitigate the risks they face, which dovetails with the argument we are making.).

In principle, health need not be rivalrous, since resources could be distributed in such a way as to ensure that everyone had equitable and adequate access to the determinants of good health (see for example ${ }^{48}$ ). In the current global economic system, the determinants of health are closely tied to the distribution of wealth and other predictors of quality of life (including labour protections), with the result that good health for some is often secured in ways that negatively affect health for others, as in the examples just described. This analysis can also be applied to health-enhancing healthcare goods, which are produced in health-endangering work environments, where the mandate that profits be optimised is prioritised over all other considerations. The obvious moral lens through which to understand this injustice is cosmopolitanism-the idea that moral consideration transcends national borders. ${ }^{49} 50$ This is appropriate when considering health-enhancing products that rely on workers from other states and regions within a globalised economy.

Cosmopolitanism requires that we do not favour one group's claims to health above another's merely on the basis of geography or any other contingent factor, so that the health-enhancing effects of healthcare goods must be considered alongside the health-endangering aspects of their production, regardless of the physical distance between the sites of benefit and harm or the citizenships of those affected. Cosmopolitanism also demands that we start from the assumption that the health needs of every person, regardless of their nationality, is equally important. It then follows that a health system that manages to provide a high standard of healthcare to its citizens because it economises by relying on products which harm citizens elsewhere is acting unjustly. If health is to be understood as rivalrous, then health justice requires all actors to be sensitive to the ways in which the improvement of health in some contexts might harm health in other contexts. This is in contrast to a 'statist' perspective, in which one sees the UK or the NHS as having special or limited obligations to its own citizens or users, and companies or government of states in which healthcare products are manufactured as having sole responsibility for their workers or citizens (see for example ${ }^{5152}$ ). Given that health is a rivalrous good which is sought against the backdrop of a globalised economy, we contend that statism is an inadequate lens through which to seek health justice, particularly in the case under study.

Finally, it is worth noting that while other forms of work may also involve serious risks and burdens for the benefit of others (eg, a nurse working on an infectious disease ward), consider that the protections offered to those producing healthcare goods are woefully inadequate, while those working in other professions and contexts tend to have protections and (sometimes) remuneration which reflect the risks and burdens they face. We can therefore say that while many workers face burdens and risks, some burdens and risks are unjust.

In short, we should be concerned about whether the production of healthcare goods is worth the cost to those who make them, and whether they are improving health as a whole, rather than just for some people. Of course, the answer lies not in rejecting masks, gloves and instruments, but rather in ensuring that the conditions of their production are such that avoidable risks to the health and well-being of workers are minimised. We turn to this in the next section.

\section{THE CASE FOR ETHICAL PROCUREMENT IN THE NHS}

The pursuit of health and socio-economic benefit within some contexts at the expense of the health of people elsewhere raises serious moral issues. Returning to the particular case of healthcare goods procurement, the NHS stands accused of contributing to health inequality, and of producing health in its own jurisdiction via the obstruction of good health in contexts where health outcomes are already inadequate. In this final section, we combat an important counter-argument, and present the case for more robust, committed ethical procurement practices within the NHS.

As we have seen, one can argue that in a publicly-funded health system there is a responsibility to obtain maximum value from public funds, which means purchasing quality healthcare goods at the lowest cost, even if doing so encourages global competition of prices and invokes complicity in the associated labour right violations. In other words, all other considerations are taken to be secondary to the prudent use of public money. After all, one could argue, the greater the saving, the greater the ability of the NHS to provide quality healthcare to a greater number of people. Further, other parties are also complicit in the harms to their workers or citizens, i.e., foreign governments, factory owners and factory management.

Yet the NHS, while described as a 'national' health service, is not exempt from the duty to consider moral issues beyond national borders. After all, as we have already noted, the NHS is critically dependent on workers trained outside the UK. Consider that half of newly registered doctors in 2018 were trained abroad, ${ }^{53}$ many from nations with severe shortages of health workers, and whose training costs were subsidised by other states. While the NHS is tasked with the objective of keeping people in its own jurisdiction healthy, its right to realise this function stops at the point at which it begins to infringe on the right of other states, health systems or communities to keep 
their people healthy. ${ }^{43}$ In this case, the NHS relies on particular goods whose production restricts the health outcomes of factory workers.

Further, we do not deny here the shared responsibility of other actors-foreign governments, factory owners and factory management-but our focus is on the particular wrong that is committed by the NHS as a global procurer and as a public health body. Not only is the NHS committed to the production of good health, but as a major procurer, it plays a particularly influential role in the supply chain, and has the potential to model responsible behaviour for other health systems. As recognised by the UK Slavery Act 2015, since pricing and other contractual stipulations are set by a main purchaser, they often have the greatest power, and therefore responsibility, to guarantee that rights are complied with in their supply chains.

As it stands, the duty to avoid causing harm while promoting health is not being adequately realised within the NHS. Whilst there is evidence of NHS supply contracts being terminated because of global price comparisons and producer substitutions, as of 2017 only one contract had been terminated due to labour rights violations, despite evidence of many such cases. ${ }^{6}$ In fact, the NHS Supply Chain's emphasis on efficient procurement based on continued savings and producer substitution ${ }^{19}$ hampers the NHS' ability to abide by its own regulations and efforts regarding working conditions in its supply chains. To address these issues, we recommend that the NHS prioritise the following: (a) paying fair prices even if this means paying slightly more for the same product; (b) eliminating chains of intermediaries by prioritising direct contracts with manufacturers; (c) establishing product/producer substitution based on labour rights compliance rather than on manufacturers and suppliers' ability to continuously lower prices and production costs; and (d) ensuring transparency in its supply chains, and in particular: informing the public that the products used to secure their health were sourced ethically, which is to say, in ways that did not harm the health of others.

\section{CONCLUSION}

The uneven global distribution of health is exacerbated by the extraction of health from certain settings and social groups to the benefit of others. In this paper we have explored a particular instance of this trend by critically examining the moral issues raised by current global procurement chains of healthcare goods, with a focus on the NHS. We have described the various labour and occupational health violations faced by those who produce healthcare goods, and have shown that the NHS is implicated in these harms through its procurement practices, which focus on driving down costs, with insufficient regard for the conditions under which the goods are produced. Health systems in highincome contexts have a duty to ensure that they do not exacerbate global health inequality, and can do so by ensuring that the products used to ensure health of people in their jurisdictions do not threaten the health of others living and working elsewhere.

Correction notice The paper has been updated since first published to amend heading levels.

Contributors AS conceptualised the project and led the theoretical design of the work. All authors conducted the research, helped draft the initial manuscript, made revisions and prepared the manuscript for submission. All three authors approved the final manuscript as submitted and agree to be accountable for all aspects of the work.

Funding The authors have not declared a specific grant for this research from any funding agency in the public, commercial or not-for-profit sectors.
Competing interests None declared.

Patient consent for publication Not required.

Provenance and peer review Not commissioned; externally peer reviewed.

\section{ORCID iDs}

Mei L Trueba http://orcid.org/0000-0002-3468-9411

Arianne Shahvisi http://orcid.org/0000-0002-9347-7566

\section{REFERENCES}

1 Prentice R, Trueba M. Precarious bodies: occupational risk assemblages in Bolivia and Trinidad. Global Labour Journal 2018;9(1):41-56.

2 Trueba M. The global dimensions of health. In: Artaraz K, Hill M, eds. Global Social Policy: Themes, issues and actors. Brighton: Palgrave, 2016: 113-33.

3 Raworth K. Trading away our rights: women working in global supply chains. Oxfam Policy and Practice: Private Sector 2004;1:1-52.

4 Bhutta MF. Fair trade for surgical instruments. BMJ 2006;333(7562):297-9.

5 Bhutta M, Roberts O. Fair and ethical trade in health: lessons from surgical instruments. The Bulletin of the Royal College of Surgeons of England 2009;91(4):120-3.

6 Bhutta MF. Time for a global response to labour rights violations in the manufacture of health-care goods. Bull World Health Organ 2017;95(5):314-314A.

7 Neu M. Just liberal violence: Sweatshops, torture, war. Rowman and Littlefield International, 2017

8 Arnold DG, Bowie NE. Sweatshops and respect for persons. Business Ethics Quarterly 2003;13(2):221-42.

9 Meyers C. Wrongful beneficence: exploitation and third World sweatshops. J Soc Philos 2004;35(3):319-33.

10 Newswire PR. Surgical Equipment: Technologies and Global Markets, October 15 2014. In: Jaekel T, Santhakumar A, eds. Healthier procurement: improvements to working conditions for surgical instrument manufacture in Pakistan. Stockholm: Swedwatch \& British Medical Association, 2015.

11 Zion Market Research. Global surgical equipment market set for rapid growth, 2018. Available: https://www.zionmarketresearch.com/news/surgical-equipment-market [Accessed 24 Feb 2020].

12 Grand View Research. Minimally Invasive Surgical Instruments Market Worth \$38.3 Billion Billion by 2025, 2019. Available: https://www.prnewswire.com/news-releases/ minimally-invasive-surgical-instruments-market-worth-38-3-billion-bn-2025-grandview-research-inc-300789717.html [Accessed 24 Feb 2020].

13 Porta F, Baruj G. Equipamiento médico: Núcleo socio-productivo estratégico. Buenos Aires: Ministerio de Ciencia, Tecnología e Innovación Productiva de la Republica de Argentina, 2012.

14 Centre for the promotion of imports from developing countries (CBI) exporting surgical instruments to Europe, 2017. Available: https://www.cbi.eu/marketinformation/medical-laboratory-devices/surgical-instruments/benelux [Accessed 24 Feb 2020].

15 BMA Medical Fair and Ethical Trade Group, Ethical Trading Initiative (ETI), and Department of Health. Ethical procurement for health: overview; 2011.

16 Office for National Statistics (ONS). Healthcare expenditure, UK health accounts: 2017, 2019. Available: https://www.ons.gov.uk/peoplepopulationandcommunity/ healthandsocialcare/healthcaresystem/bulletins/ukhealthaccounts/2017 [Accessed 24 Feb 2020].

17 Bhutta M, Santhakumar A. In good hands: tackling labour rights concerns in the manufacture of medical gloves. British Medical Association, BMA Medical Fair and Ethical Trade Group \& European Working Group on Ethical Public Procurement (EWGEPP), 2016.

18 Jaekel T, Swedwatch, Santhakumar A. Healthier procurement: improvements to working conditions for surgical instrument manufacture in Pakistan. Stockholm: Swedwatch \& British Medical Association, 2015.

19 Public Health England \& NHS. Better procurement better value better care: a procurement development programme for the NHS, 2013. Available: https://assets. publishing.service.gov.uk/government/uploads/system/uploads/attachment_data/ file/226835/procurement_development_programme_for_NHS.pdf [Accessed 24 Feb 2020].

20 Prentice R, De Neve G. Unmaking the global sweatshop: health and safety of the world's garment workers. University of Pennsylvania Press, 2017.

21 Trueba ML. 'Looking at risk with both eyes': health and safety in the Cerro Rico of Potosí (Bolivia) [PhD Thesis]. Sussex University-Institute of Development Studies, 2014.

22 Trade Union Congress (TUC). Dust in the workplace. guidance for health and safety representatives, 2011. Available: https://www.tuc.org.uk/sites/default/files/ DUSTWorkplace.pdf [Accessed 17 Feb 2020]

23 Nadvi K, Halder G. Local clusters in global value chains: exploring dynamic linkages between Germany and Pakistan IDS Working Paper; 2002.

24 NHS Supply Chain. Supplier code of conduct, 2020. Available: https://wwwmedia supplychain.nhs.uk/media/supplier_conduct_code.pdf [Accessed 10 Feb 2010].

25 Shahvisi A, Trueba M. PPE may protect us, but it harms the sweatshop workers who make it. BMJ Medical Ethics Blog. Available: https://blogs.bmj.com/medical-ethics/ 2020/05/07/ppe-may-protect-us-but-it-harms-the-sweatshop-workers-who-make-it/ [Accessed 16 Jun 2020]. 
26 Chowdhury SNM, Moni D. A situation analysis of the menstrual regulation programme in Bangladesh. Reprod Health Matters 2004;12(24 Suppl):95-104.

27 Gumodoka B, Favot I, Berege ZA, et al. Occupational exposure to the risk of HIV infection among health care workers in Mwanza region, United Republic of Tanzania. Bull World Health Organ 1997;75(2):133-40.

28 Maimbolwa MC, Ransjö-Arvidson $\mathrm{AB}, \mathrm{Ng}^{\prime}$ andu $\mathrm{N}$, et al. Routine care of women experiencing normal deliveries in Zambian maternity wards: a pilot study. Midwifery 1997;13(3):125-31

29 Duerink DO, Farida H, Nagelkerke NJD, et al. Preventing nosocomial infections: improving compliance with standard precautions in an Indonesian teaching hospital. J Hosp Infect 2006;64(1):36-43.

30 Ansa VO, Udoma EJ, Umoh MS, et al. Occupational risk of infection by human immunodeficiency and hepatitis B viruses among health workers in south-eastern Nigeria. East Afr Med J 2002;79(5):254-6.

31 Croitoru C, Stanek A. Far away from the NHS - Hernia Surgery in Nigeria and Kenya. Ulster Med J 2018;87(1):11-16.

32 Tortorella GL, Fogliatto FS, Anzanello M, et al. Making the value flow: application of value stream mapping in a Brazilian public healthcare organisation. Total Quality Management \& Business Excellence 2017;28(13-14):1544-58.

33 Fitzgerald E, Bhutta MF. Tooling up: how the Lifebox Foundation are using safe surgical instruments as a lever to lift the operative ecosystem in global surgery. Bulletin of the Royal College of Surgeons of England 2018;100(6):269-70.

34 Ramirez Corone M. Dispositivos medicos exportamos pero no consumimos, 2018. El Economista 06 March 2018. Available: https://www.eleconomista.com.mx/opinion/ Dispositivos-medicos-exportamos-pero-no-consumimos-20180306-0120.html [Accessed 24 Feb 2020].

35 Morrissey 0, Te Velde DW, Hewitt A. Defining international public goods. in: international public goods. Springer 2002:31-46.

36 Wilkinson R, Pickett K. The spirit level: why equality is better for everyone. UK: Penguin, 2010.

37 Eckhardt J, Lee K. The international political economy of health. In: The Palgrave Handbook of contemporary international political economy. London: Palgrave Macmillan, 2019: 667-82.
38 Krieger N. Epidemiology and the people's health: theory and context. Oxford University Press, 2011

39 WHO. World health statistics 2016: monitoring health for the SDGs. Available: http:// www.who.int/gho/publications/world_health_statistics/2016/en/ [Accessed $28 \mathrm{Sep}$ 2018].

40 Brock G, Pogge T. Global Tax justice and global justice. Moral Philosophy and Politics 2014;1:1-15.

41 Benatar SR, Gill S, Bakker I. Global health and the global economic crisis. Am J Public Health 2011;101(4):646-53.

42 Ahmad OB. Managing medical migration from poor countries. BMJ 2005;331(7507):43-5.

43 Shahvisi A. Health worker migration and migrant healthcare: seeking cosmopolitanism in the NHS. Bioethics 2018;32(6):334-42.

44 Hamilton JT. Testing for environmental racism: prejudice, profits, political power? Journal of Policy Analysis and Management 1995;14(1):107-32.

45 Ethirajan A. Sri Lankans demand UK take back rotting waste, 2019. BBC News 24 July 2019. Available: https://www.bbc.co.uk/news/world-asia-49100887 [Accessed $07 \mathrm{Apr}$ 2020].

46 Clapp J. Toxic exports: the transfer of hazardous wastes from rich to poor countries. Cornell University Press, 2001.

47 Swaney JA. So What's Wrong with Dumping on Africa? J Econ Issues 1994;28(2):367-77.

48 Ooms G, Hammonds R. Taking up Daniels' challenge: the case for global health justice. Health Hum Rights 2010;12(1):29-46.

49 Brock G. Global justice, cosmopolitan duties and duties to compatriots: the case of healthcare. Public Health Ethics 2015:8(2):110-20.

50 Brown GW. Distributing who gets what and why: four normative approaches to global health. Glob Policy 2012;3(3):292-302.

51 Tamir Y. Liberal nationalism. Princeton: Princeton University Press, 1993.

52 Miller RW. Cosmopolitan respect and Patriotic concern. Philos Public Aff 1998:27(3):202-24.

53 General Medical Council. The state of medical education and practice in the UK; 2019 